\title{
ILHA DE CALOR EM TEODORO SAMPAIO/SP - RELAÇÃO ENTRE BAIRROS
}

Andreza Benvindo Soares, lesmin Yamada Ubida, Ítalo Murilo de Souza Borges, Maria Alessandra Bacaro Boscoli

Universidade do Oeste Paulista - UNOESTE, Presidente Prudente, SP. E-mail: andreza benvindo@hotmail.com; iesmin.ubida@gmail.com; italomsborges2010@hotmail.com; allyboscoli@gmail.com

\section{RESUMO}

Com a rápida expansão urbana e o crescente número de casas, a questão ambiental está cada vez mais prejudicada, sendo ignorada por muitos ou não tendo conhecimento de sua importância com os seus vários benefícios. A arborização em ruas está cada vez mais escassa e isso acaba criando ilhas de calor, por não ter tantas áreas permeáveis e vegetação para causar frescor e diminuição do calor. 0 presente artigo deseja mostrar uma comparação entre três bairros no município de Teodoro Sampaio - SP, correlacionando-os com suas temperaturas em um determinado período do dia, e apontando as possíveis causas dessas mudanças bruscas de temperatura em uma cidade interiorana. Para a da coleta de dados necessárias, foram realizados transectos em dois dias diferentes, onde ficou explícito a interferência do homem de forma incorreta e como isto pode ser prejudicial não só a estrutura urbana, mas também a saúde da população.

PALAVRAS-CHAVE: Teodoro Sampaio; Transecto; Ilhas de calor.

\section{ISLAND OF HEAT IN TEODORO SAMPAIO - RELATIONSHIP BETWEEN NEIGHBORHOODS}

\begin{abstract}
With rapid urban expansion and increasing numbers of homes, the environmental issue is increasingly undermined, being ignored by many or unaware of its importance with its various benefits. The afforestation in streets is increasingly scarce and this ends up creating islands of heat, for not having so many permeable areas and vegetation to cause freshness and decrease of heat. The present article wishes to show a comparison between three districts in the municipality of Teodoro Sampaio - SP, correlating them with their temperatures in a given period of the day, and pointing out the possible causes of these sudden changes in temperature in an interior city. For the necessary data collection, transects were carried out on two different days, where the interference of the man was incorrectly explained and how this can be harmful not only the urban structure, but also the health of the population.
\end{abstract}

KEYWORDS: Teodoro Sampaio; Transect; Islands of heat.

\section{INTRODUÇÃO}

A Revolução Industrial do século XIX alavancou na questão tecnológica e econômica com sua rápida troca dos produtos manufaturados pelos produzidos em larga escala, tendo várias indústrias para suprir essas novas demandas exigidas por esse novo mercado. Com isso, precisou-se de grandes contingentes de mão de obra, desencadeando um forte êxodo rural, o que influenciou na concepção do espaço urbano, pois não conseguiu suprir a demanda populacional, e com isso foi forçada a se expandir de maneira desordenada. 
Essa concentração de linhas de produção, construções e pessoas dentro das cidades, geraram um grande impacto ambiental por sua intensa emissão de gases poluentes, danificando a atmosfera e a saúde da sociedade.

Atividades humanas, como o desenvolvimento de indústrias e a ampla utilização de veículos automotores, mostra a diferença de temperatura entre os dois meios sendo a temperatura em grandes centros das cidades mais altas do que as das periferias e áreas rurais, o que vêm causando mudanças na composição da atmosfera por meio de um contínuo aumento nas concentrações dos poluidores do ar, conhecidas como gases de efeito estufa, como o dióxido de carbono. Essa alta densidade populacional em um único ponto, e as escolhas dos materiais construtivos, podem também afetar e relacionar na temperatura urbana.

Segundo Chen (2006) e Imhoff, (2010), o aquecimento global tem recebido mais atenção devido ao perceptível aumento da temperatura média desde os finais do século XIX, sendo um dos fatores predominantes nessa mudança climática o fenômeno do aquecimento urbano, decorrente dessa rápida modificação tanto em intensidade como em área física, existindo um interesse crescente na saúde humana e no clima, decorrente desse aquecimento global.

As ilhas de calor são regiões de uma cidade que possuem uma temperatura diferente do restante, tornando literalmente uma ilha de calor. Essa diferença pode variar de $4^{\circ} \mathrm{C}, 6^{\circ} \mathrm{C}$ ou até mesmo $11^{\circ} \mathrm{C}$, gerando transtornos com a temperatura excessiva à população, o que inflige no orçamento familiares com equipamentos para sanar esse incômodo.

Segundo OKE (1987; 1988) e Santander \& Baldasso (2014) a malha urbana modifica as principais entradas e saídas radiativas e energéticas (fluxos de calor e calor armazenado), sendo essas modificações apontadas como as principais causas das ilhas de calor. Os fatores que levam a esse fenômeno são principalmente: a substituição da cobertura vegetal por malha asfáltica, a concentração populacional, a verticalização das metrópoles atuais e a impermeabilização do solo.

Nesta vertente, o presente artigo tem como objetivo principal apresentar as variações de temperatura em um único ambiente urbano da cidade Teodoro Sampaio, verificando-se através das coletas de dados se realmente acontece uma ilha de calor. Sendo uma das possíveis causam da mesma a falta de arborização e a escolha dos materiais construtivos. Por tanto foi correlacionando três bairros da cidade, Vila Furlan, Bairro da Estação (nome popular) e a CDHU.

Para tanto fez-se necessário levantamentos bibliográficos para a compreensão de conceitos pertinentes, as principais causas e essencialmente levantamentos in loco com um termômetro eletrônico, em busca de dados, observações do entorno de todos os pontos e uma análise geral.

\section{METODOLOGIA}

Teodoro Sampaio - SP, é um município localizado na porção do oeste paulista, no interior do estado de São Paulo, estando em uma altitude de 352 metros acima do nível do mar, segundo o site da Prefeitura Municipal da cidade, contendo uma população de aproximadamente 22795 habitantes, segundo o IBGE de 2016, sendo então um município interiorano de porte pequeno.

Mesmo as ilhas de calor sendo predominantes em grandes centros urbanos, isto não significa que não se encontre em cidades pequenas e de densidade demográfica baixa. 
FIGURA 1 - Localização do município de Teodoro Sampaio em relação ao estado de São Paulo.

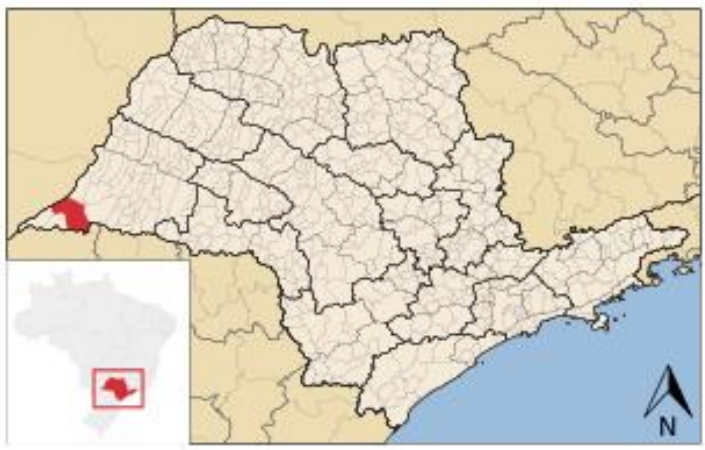

Fonte: Raphael Lorenzeto de Abreu, 2006. Editado pelos autores, 2017.

Para isso, foi escolhido uma região da cidade em que pôde relacionar três bairros, o Vila Furlan, CDHU e o bairro da Estação. Como pode-se visualizar na figura 2, o CDHU se localiza entre esses dois bairros, e que apresenta características de um bairro novo, tendo pouca arborização, existindo somente as de pequeno porte, onde os mesmos, por estarem no porte adulto, não favorece o clima local, além da sua região estar praticamente impermeabilizada por completo. Sabe-se que, nesses empreendimentos não se dá a importância a qualidade, mas sim a rápida comercialização dos mesmos, pois o anseio da população é pelas residências e não pelo contexto onde serão inseridos, e nem pela preocupação de que esses espaços estão ou não sendo bem articulados e planejados para melhor atendê-los.

FIGURA 2 - Transecto realizado dentro do município de Teodoro Sampaio/SP, pontos inicial e final.

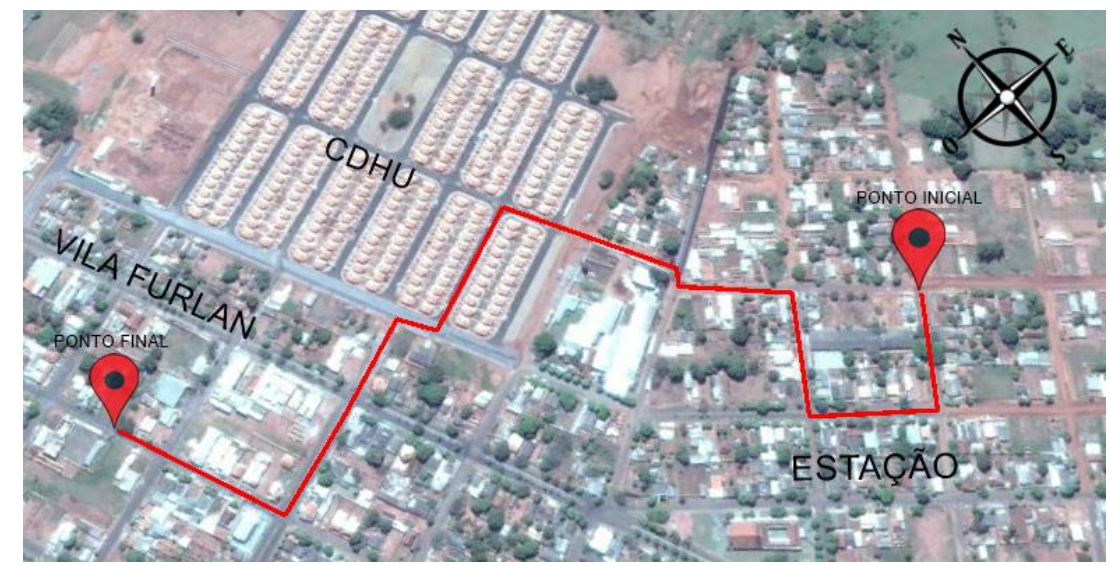

Fonte: Google Earth, 2016. Editado pelos autores, 2017.

Para a constatação de uma ilha de calor, foi realizado um transecto, com um percurso de 1132 metros, sendo divididos em 20 pontos, com 50 metros de distância entre eles, coletando as temperaturas de cada parada com um termômetro eletrônico, perpassando entre três bairros, em três dias, 29/04/2017 e 13/05/2017, entre 18:50hs e 20hs, do período noturno, e no dia 04/05/2017 às $13: 30 \mathrm{hs}$ a $14 \mathrm{hs}$ foi realizado um levantamento fotográfico no período diurno para melhor análise. Com esse levantamento fotográfico, pode constatar essa estrita relação entre o clima e a arborização local, além da escolha do material construtivo e a falta de áreas permeáveis. 
A escolha específica do horário para essas medições do transecto se deu pelo fato da quantidade de calor absorvido dos materiais construtivos das casas da cidade de Teodoro Sampio, em que, por serem a maioria de alvenaria, seu calor absorvido seria devolvido ao meio em que se localiza aproximadamente depois de uma a três horas depois do por do sol, e é nesse momento em que as ilhas de calor são encontradas.

\section{RESULTADO}

No primeiro dia de medições, partindo do bairro Estação e finalizando na Vila Furlan, o dia estava com uma variação de nebulosidade com períodos curtos de sol intercalados com períodos de nuvens, com uma velocidade do vento em $6 \mathrm{~km} / \mathrm{h}$.

Durante o percurso, do ponto 1 ao ponto 8 existiu uma estabilidade de temperatura, variando somente $0,5 \mathrm{O} C$. Porém, ao adentrar no bairro $\mathrm{CDHU}$, no ponto 9 , houve uma queda brusca de temperatura de 1,5 ․ C. A partir do ponto 10 ao 20 , teve outra estabilidade, existindo pouca variação na temperatura, como mostra o gráfico da figura 3.

FIGURA 3 - Gráfico do dia 29/04/2017.

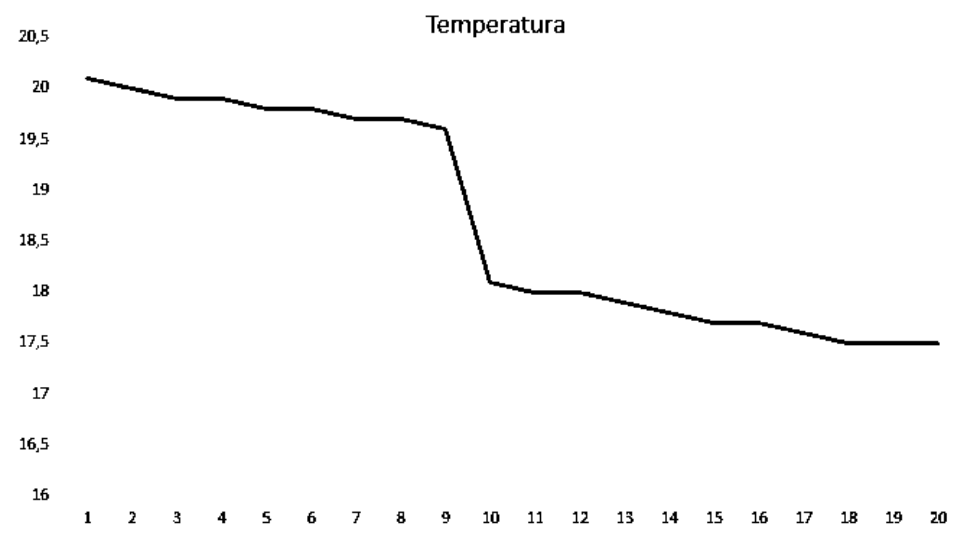

Fonte: Editado pelos autores, 2017.

No segundo dia de medições, partindo do mesmo ponto, o dia estava com uma nebulosidade, com períodos curtos de céu aberto, com uma velocidade do vento em $7 \mathrm{~km} / \mathrm{h}$. O dia estava mais fresco e com grande possibilidade de chuva, mas que também foi possível localizar a ilha de calor.

Novamente, a ilha de calor no bairro da CDHU se manifestou, existindo uma estabilidade até aproximadamente o ponto 8 e depois caindo 0,4 으, e depois existindo uma estabilidade novamente, como mostra o gráfico da figura 4.

FIGURA 4 - Gráfico do dia 13/05/2017.

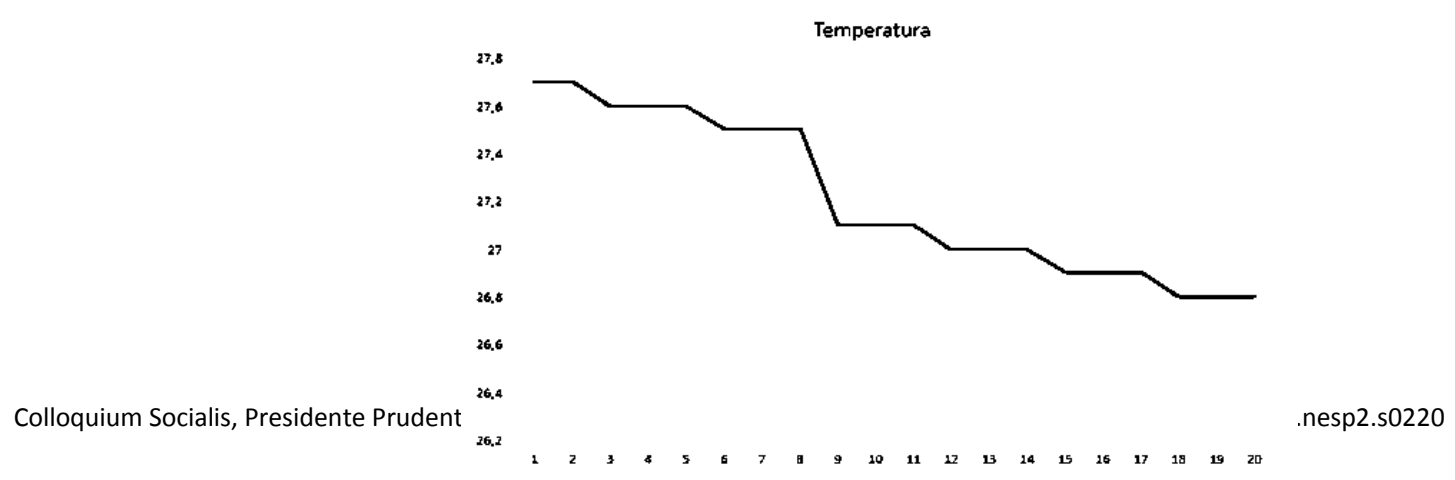


Fonte: Editado pelos autores, 2017.

Comparando os dois gráficos, a ilha de calor ficou evidente, que, através das medições de temperatura desse percurso em diferentes dias mostrou uma variação de temperatura no mesmo ponto, que seria a entrada do bairro CDHU.

FIGURA 4 - Gráfico do dia 13/05/2017

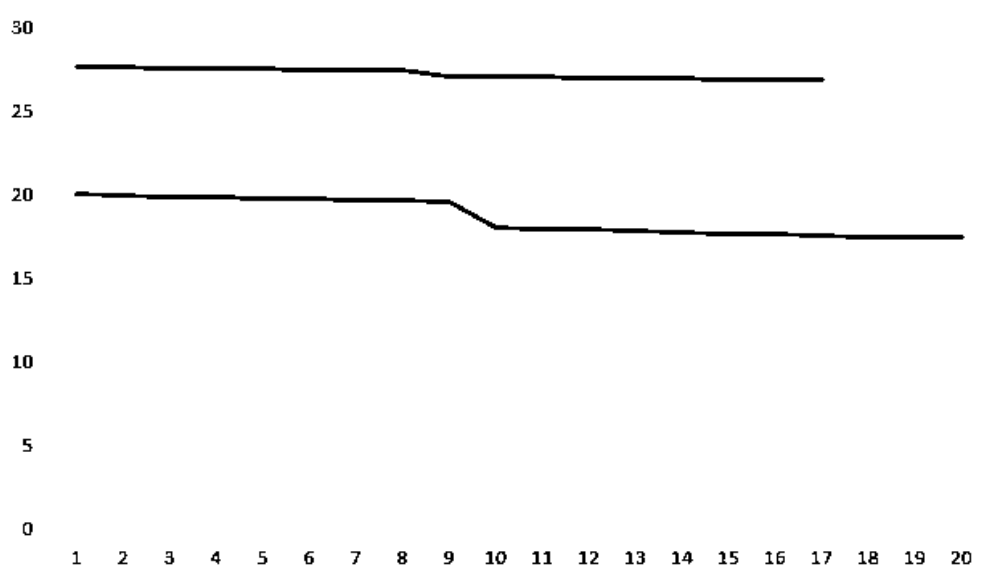

Fonte: Editado pelos autores, 2017.

\section{CONSIDERAÇÕES FINAIS}

Por fim, através da análise realizada pelo grupo, foi evidenciada uma ilha de calor no bairro CDHU. Nos dois dias do transecto, o ponto 9 (nove) foi um "divisor de águas" no que diz respeito ao espaço físico existente e para as medições, pois este local é a divisa do bairro da Estação e da CDHU e, portanto, foi apontado uma queda brusca de temperaturas em poucos metros de distância em ambos os dias.

Para uma cidade de pequeno porte como Teodoro Sampaio- SP, essa diferença de temperatura $\left(1,5^{\circ} \mathrm{C}-0,4^{\circ} \mathrm{C}\right)$ é grande e mostra como a falta de planejamento urbano afeta a vida dos cidadãos.

A importância do estudo térmico está no fato do mesmo ser determinante nas condições de bem-estar para todos os seres humanos nos espaços em que vivenciam. Sem dúvida, a presença de vegetação é um condicionante fundamental no estudo da temperatura urbana.

Mesmo que o poder público e privado não dê a devida atenção, é necessário um estudo detalhado e cuidadoso em qualquer localidade onde será inserida uma residência, bairro ou cidade, além de prever e controlar o crescimento desordenado e a impermeabilização incessante dos centros urbanos para que evite a formação de mais ilhas de calor.

\section{REFERÊNCIAS BIBLIOGRÁFICAS}

CHEN, X.L.; ZHAO, H.M.; LI, P.X.; YIN, Z.Y. Remote sensing image-based analysis of the relationship between urban heat island and land use/cover changes. Remote Sensing of Environment, New York, v.104, p.133-146, 2006. https://doi.org/10.1016/j.rse.2005.11.016 
IMHOFF, M.L.; ZHANG, P.; WOLFE, R.E.; BOUNOUA, L. Remote sensing of the urban heat island effect across biomes in the continental USA. Remote Sensing of Environment, New York, v.114, p.504-513, 2010. https://doi.org/10.1016/j.rse.2009.10.008

SANTANDER, Leonardo Vidouto; BALDASSO, Rafael Felipe de Freitas. Ilhas de calor e suas consequências na região metropolitana de São Paulo. BE_310 CIÊNCIAS DO AMBIENTE - UNICAMP ESTUDOS Turma 2014. Disponível em: http://www.ib.unicamp.br/dep_biologia_animal/BE310. Acesso em: 12/08/2017.

FREITAS, Eduardo de. Ilha de calor; Brasil Escola. Disponível em <http://brasilescola.uol.com.br/geografia/ilha-de-calor.htm>. Acesso em 12 de agosto de 2017.

Site da Prefeitura de Teodoro Sampaio. Disponível em: http://www.teodorosampaio.sp.gov.br/index2.php?pag=T1RjPU9EZz1PVFU9T0dVPU9HST1PVEE9T0d FPU9HRT0=\&idmenu=214. Acesso em: 12/08/2017

IBGE - Instituto Brasileiro de Geografia e Estatística. Disponível em: http://www.cidades.ibge.gov.br/painel/historico.php?codmun=355430. Acesso em 12/08/2017 